\title{
Seroprevalence of Hepatitis B Virus among Patients at a Tertiary Care Centre in North Karnataka, India
}

\author{
Shilpa K. Gokale, Suresh B. Sonth* and Shivakumar S. Solabannavar \\ Department of Microbiology, S N Medical College, Navanagar, Bagalkot, \\ Karnataka 587103, India \\ *Corresponding author
}

\section{A B S T R A C T}

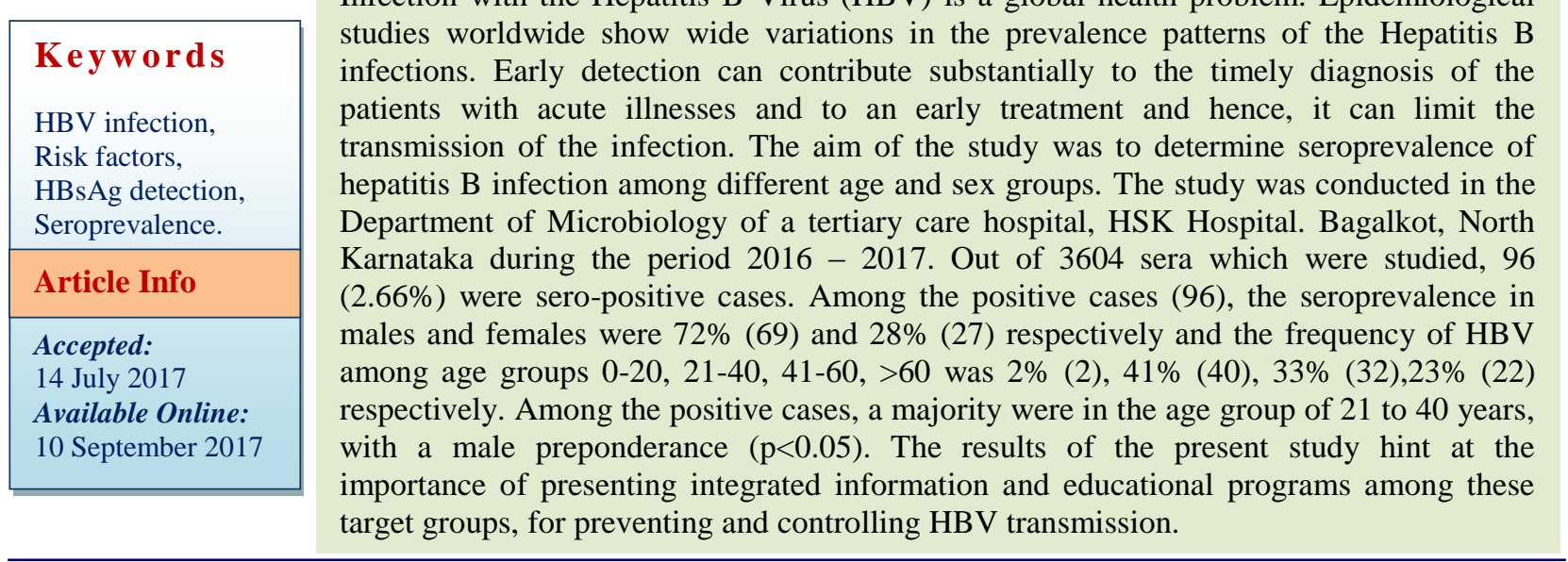

\section{Introduction}

Hepatitis B virus (HBV) infection is one of the major global health problems. Of the approximately 2 billion people, who have been infected worldwide more than 350 million are chronic carriers of HBV (1).

Countries are classified on the basis of endemicity of hepatitis B virus (HBV) infection into high ( $8 \%$ or more), intermediate (2- $7 \%$ ) or low (less than 2\%) incidence countries. The prevalence of chronic HBV infection in India ranges from $2 \%$ to $10 \%$ as shown by different studies $(1,2,3)$. India therefore comes under the intermediate to high endemicity category.
HBV infection is predominantly acquired at an early age in developing countries, which includes vertical transmission from mother to child, perinatal transmission, and horizontal transmission from child to child. However HBV can also be transmitted sexually (both homo and hetero sexual) accounts for a majority of the transmission occurring in adult life (4).

The clinical spectrum of HBV infection ranges from subclinical to acute symptomatic hepatitis or rarely fulminant hepatitis during the acute phase, inactive carrier state to chronic hepatitis. HBsAg is the first 
seromarker to indicate active HBV infection either acute or chronic. It would appear in patient's serum usually 2-10 weeks after being infected with HBV before liver enzymes are increased or clinical symptoms appear (2).

Sero-surveys are one of the primary methods to determine the prevalence of HBsAg. There are very few studies which are available regarding the prevalence of $\mathrm{HBV}$ among the patients in the northern part of Karnataka. Hence the present study was undertaken to estimate the seroprevalence of $\mathrm{HBV}$ in both sexes and different age groups in our hospital.

\section{Materials and Methods}

The present study was carried out in patients attending outpatient and inpatient departments of our tertiary care hospital, Bagalkot, India.

These tests were done as part of preoperative screening, antenatal screening, screening on haemodialysis patients, on patients suspected to have HBV infection after getting a verbal consent. The sera were screened for the presence of HBsAg by a rapid immunochromatographic (ICT) test.

Those found positive on screening test were confirmed by third generation ELISA kits (Hepalisa; J Mitra and Co. Pvt. Ltd., New Delhi, India) according to the manufacturers protocol. The results were analyzed using chisquare test.

\section{Results and Discussion}

Out of 3604 individuals screened between August 2016 to January 2017, 96 (2.66\%) were HBsAg positive. The age and sex wise distribution of individuals were shown in table 1. Among the positive cases (96), the seroprevalence in males and females was $72 \%$ (69) and $28 \%$ (27) respectively and the frequency of HBV among age groups 0-20, $21-40,41-60,>60$ was $2 \%$ (2), 41\% (40), $33 \%$ (32), 23\% (22) respectively. Highest prevalence was observed among subjects of 21-40 years age group, followed by 41-60 years age group with male preponderance $(\mathrm{p}<0.05)$.

In the present study, the seroprevalence was found to be $2.66 \%$.In a study conducted in a hospital-based population at Kathmandu Medical College Hospital, Nepal, the prevalence rate was found to be $2.5 \%$ (5). Chowdhury A reported that $3-4 \%$ of the Indian population is HBV infected with the highest prevalence among the aborigines of Andaman as well as from Arunachal Pradesh (6). In our study, there was an increase in the prevalence among the male population as compared to that in females. Dutta et al., has found that the HBsAg positivity rate $35.3 \%$ in male and $19.3 \%$ in female. They observed that hepatitis B infection is more common in male although the sample size was small (7).

In another study of P. Jain et al., also found that the positivity of $\mathrm{HbsAg}$ was more prevalent among males $62.54 \%$ in comparison to female $23.22 \%$ (8). Another observation by Quadri et al., documented that the prevalence of HBsAg is higher in males than females (9). Quamer et al., explained the probable cause of females are suffering from Hepatitis B infection less than male because females probably clear HBV more efficiently in comparison to males(10).

The incidence was highest among 21-40 years age group and lowest among 0-20 years. Thus these data indicate that the prevention of perinatally transmitted $\mathrm{HBV}$ in this locality by immunization and improvements in living standards of South Indian population. In contrast to our study, Singh et al., reported highest incidence among $<5$ years and then a progressive decline thereafter (11). 
Table.1 Age and sex distribution of patients testing for $\mathrm{HBsAg}$

\begin{tabular}{|l|l|l|l|l|l|l|}
\hline \multirow{2}{*}{$\begin{array}{l}\text { Age of patients in } \\
\text { years }\end{array}$} & Males & Females & \multicolumn{2}{l|}{ Total } \\
\cline { 2 - 7 } & Tested & Positive & Tested & Positive & Tested & Positive \\
\hline $0-20$ & 75 & 2 & 23 & 0 & 98 & 2 \\
\hline $21-40$ & 1088 & 29 & 398 & 11 & 1486 & 40 \\
\hline $41-60$ & 938 & 25 & 255 & 7 & 1193 & 32 \\
\hline$>60$ & 489 & 13 & 338 & 9 & 827 & 22 \\
\hline Total & 2590 & 69 & 1014 & 27 & 3604 & 96 \\
\hline
\end{tabular}

In endemic country like India, where diagnostic facilities are poor in peripheral areas, rapid immunochromatographic tests make an excellent tool in addressing this potentially fatal, epidemic prone infection. Routine screening, health education and HBV vaccinations are the methods adopted to reduce the morbidity and mortality of HBV infection in the community.

\section{References}

1. Hepatitis B: Fact sheets WHO (http://www.who.int/mediacentre/fact sheets/ fs204/en).

2. Previsani N, Lavanchy D. World Health Organization. Hepatitis B (WHO/CDS/CSR/LYO/ 2002.2). 2002.

3. Gupta S, Gupta R, Joshi YK, Singh S. Role of Horizontal Transmission in Hepatitis B Virus Spread among Household Contacts in North India. Intervirology 2008; 51: 7-13.

4. Hou J, Liu Z, Gu F. Epidemiology and prevention of Hepatitis B Virus Infection. Int J Med Sci. 2005; 2(1): 50-57.

5. Bhatta CP, Thapa B, Rana BB. Seroprevalence of Hepatitis B in Kathmandu Medical College Teaching Hospital. Kathmandu Univ Med J (KUMJ) 2003; 1: 113-6.

6. Chaudhary IA, Khan SS, Majrooh MA, Alvi AA. Seroprevalence of hepatitis B and C among patients reporting in a surgical OPD at Fauji Foundation Hospital, Rawalpindi:
Review of 5 year literature. Pak J Med Sci. 2007; 23: 514-7.

7. Dutta S, Shivananda PG, Chatterjee A. Prevalence of hepatitis B surface antigen and antibody among hospital admitted patients in Manipal. Indian J Public Health. 1994; 38: 108-12.

8. Jain P, Prakash S, Gupta S., Singh K.P, Shrivastava S, Singh D, D, Singh J, Jain A. - Prevalence of Hepatitis A virus, hepatitis $B$ virus, hepatitis $C$ virus, hepatitis $D$ virus, and hepatitis $\mathrm{E}$ virus a cause of acute viral hepatitis in North India-A hospital based study - Indian J. Med Microbiology, 2013; 31: $261-5$.

9. Sayad A. Quadri, H.J. Dadapeer, K. Mohammed Arifulla and Nazia Khan Prevalence of Hepatitis B surface antigen in hospital based population in Bijapur, Karnataka. Al Ameen J. Med. Sci., 2013; 6(2); 180-182.

10. Quamer S, shahab T, Alam S, Malik A, Afzal K, - Age specific prevalence of Hepatitis B surface antigen in pediatric population of Aligarh, North India- Indian Journal of Pediatr., 2004; 71; 965 -7.

11. Singh J, Prakash C, Gupta RS, Bora D, Jain DC, Datta KK. Epidemiology of endemic viral hepatitis in an urban area of India: a retrospective community study in Alwar. Bull World Health Organ. 1997; 75(5): 4638.

\section{How to cite this article:}

Shilpa K. Gokale, Suresh B. Sonth and Shivakumar S. Solabannavar. 2017. Seroprevalence of Hepatitis B Virus among Patients at a Tertiary Care Centre in North Karnataka. Int.J.Curr.Microbiol.App.Sci. 6(9): 755-757. doi: https://doi.org/10.20546/ijcmas.2017.609.093 